\title{
Fitorremediação de solo contaminado com herbicidas inibidores de FSII e de ALS
}

\author{
Phytoremediation of soil contaminated with ALS and PS II \\ inhibitors herbicides
}

\section{Leandro Galon ${ }^{1 *}$, Felipe Nonemacher ${ }^{1}$, Luciane Renata Agazzi ${ }^{1}$, Renan Carlos Fiabane ${ }^{1}$, Cesar Tiago Forte ${ }^{2}$, Milena Barretta Franceschetti ${ }^{1}$, Gismael Francisco Perin ${ }^{1}$}

Resumo - Ao se usar herbicidas para o controle de plantas daninhas esses produtos podem permanecer no solo e causar problemas em culturas cultivadas em sucessão, processo esse conhecido como carryover. Pode-se usar como alternativa, para descontaminação de solos com herbicidas a técnica da fitorremediação. Sendo assim, objetivou-se com o trabalho avaliar o potencial fitorremediador das espécies, ervilhaca, nabo, centeio, soja-preta e capim-colonião cultivadas em solos contaminados com atrazine e chlorimuron-ethyl + sulfometuron-methyl. Os herbicidas foram aplicados em pré-emergência das espécies, sendo instalados dois experimentos. No primeiro ensaio testou-se o potencial fitorremediador das espécies e no segundo usou-se o pepino como cultura bioindicadora para comprovar se houve a despoluição do solo. As variáveis avaliadas aos 40 dias após e emergência (DAE) foram: fitotoxicidade (\%), altura $(\mathrm{cm})$ e a massa seca da parte aérea das plantas $(\mathrm{g})$. A mistura chlorimuron-ethyl + sulfometuron-methyl causou os maiores sintomas de fitotoxicidade tanto nas espécies fitorremediadoras, como para a cultura bioindicadora. Os resultados demonstram que a soja-preta apresentou maior potencial de fitorremediação de solo contaminado com chlorimuron-ethyl + sulfometuron-methyl e o capim-colonião foi a espécie que demonstrou potencial satisfatório como planta fitorremediadora de solo contaminado com atrazine. O pepino teve maior crescimento quando se usou o capim-colonião como planta fitorremediadora de solo tratado com atrazine, principalmente nas maiores doses aplicadas. Até a dose recomendada o centeio apresentou capacidade de despoluir o solo tratado com chlorimuron-ethyl + sulfometuron-methyl.

Palavras-chave: carryover, fitorremediação de solo, sustentabilidade dos agroecossistemas

Abstract - Alternative to decontaminate the soil is the phytoremediation practice. In this way, this study aimed to evaluate the phytoremediation potential of the following species: vetch, radish, cereal rye, black soybean and colonião grass, grown in a soil contaminated with atrazine and chlorimuron-ethyl + sulfometuron-methyl. The herbicides were applied in pre-emergence of the species. Two experiments were installed, the first one tested the phytoremediation potential of the species and the second one used the cucumber as bioindicator culture to prove if the soil had been depolluted. The variables evaluated at 40 days after emergence (DAE) were: phytotoxicity $(\%)$, height $(\mathrm{cm})$ and dry mass of the aerial part of the plants $(\mathrm{g})$. There is a great variation in the selectivity of the cultures to the two herbicides, and the chlorimuron-ethyl + sulfometuron-methyl mixture presented the highest phytotoxicity symptoms, both for the phytoremediation species and for the bioindicator culture.

Recebido: Outubro 30, 2017. Aceito: Fevereiro 14, 2018.

${ }^{1}$ Universidade Federal da Fronteira Sul - UFFS, ERS 135, km 72, número 200, Caixa Postal 764, CEP 99700-970, Interior de Erechim/RS, Campus Erechim, Brasil. E-mail: leandro.galone@gmail.com; felipe.nonemacher@hotmail.com; luci_agazzi@hotmail.com; renanfiabane@hotmail.com; milena.barretta@hotmail.com; gismaelperin@gmail.com

2 Programa de Pós-Graduação em Ciência e Tecnologia Ambiental - PPGCTA, Universidade Federal da Fronteira Sul - UFFS, Campus Erechim/RS, Brasil. E-mail: cesartiagoforte@hotmail.com 
The results allowed to conclude that the management the black soybean presented a greater potential of phytoremediation of soil contaminated with chlorimuron-ethyl + sulfometuron-methyl and that the colonium grass was the species that demonstrated satisfactory potential as phytoremediation plant of contaminated soil with atrazine.

Keywords: carryover, soil phytoremediation, agro-ecosystems sustainability

\section{Introdução}

No atual modelo de agricultura, destaca-se a utilização de inúmeras tecnologias que proporcionem o aumento da produtividade. Em se tratando de culturas produtoras de grãos, o Brasil apresenta uma área aproximada de 22 milhões de ha (FAOSTAT, 2017). Vários são os desafios encontrados pelos produtores, um deles é o controle satisfatório de plantas daninhas infestantes das lavouras. Entre os métodos de controle, o químico torna-se prática indispensável para a agricultura em larga escala, por sua menor dependência de mão de obra, eficiência e rapidez no manejo das plantas daninhas se considerado a outros métodos de controle (Santos et al., 2013).

Para a realização do controle das principais plantas daninhas infestantes de culturas, é necessária a utilização de herbicidas de diferentes mecanismos de ação, e em alguns casos que apresentem efeito residual prolongado no solo para se evitar o refluxo dessas espécies. Quando os herbicidas são aplicados nas lavouras, uma proporção atinge o solo, seja por aplicação direta, por escorrimento das folhas ou por incorporação no processo de degradação das plantas (Kraemer et al., 2009), podendo ocasionar problemas tanto de contaminação ambiental como nos cultivos posteriores pelo processo conhecido como carryover.

Os herbicidas pertencentes aos grupos químicos das triazinas e das sulfoniluréias apresentam características físico-químicas que lhes permitem persistir no ambiente por longos períodos. Porém, a permanência desses herbicidas no solo como moléculas ainda ativas pode causar problemas em culturas cultivadas em sucessão (Mancuso et al., 2011; Santos et al., 2012). Além disso, muitos desses herbicidas de longo efeito residual podem lixiviar para camadas mais profundas do solo e contaminar lençóis freáticos (Santos et al., 2012).

O sulfometuron-methyl é um herbicida que apresenta efeito residual, sendo amplamente utilizado em cultivos florestais ou em lavouras de cana de açúcar (Osiecka e Minogue, 2012). Já atrazina é usada para o manejo de plantas daninhas infestantes de milho, sorgo e cana-de-açúcar, sendo que apresentou intoxicação da aveia quando essa foi semeada 150 dias após a aplicação do herbicida na cultura do milho (Silva et al., 2007a).

Existem técnicas promissoras que visam amenizar ou até mesmo sanar esses efeitos residuais dos herbicidas, trata-se da fitorremediação, método que consiste na utilização de espécies vegetais como agentes descontaminantes do solo. A fitorremediação consiste no processo de seletividade natural ou resistência desenvolvida por espécies vegetais à algum herbicida ou agente xenobiótico (Pires et al., 2003).

A fitorremediação está diretamente relacionada com a composição do solo, com a capacidade da planta em extrair estes compostos orgânicos (fitoextração), e com a diversidade de microrganismos presentes no solo capazes de favorecer o processo (fitoestimulação), através do aproveitamento de exsudatos radiculares (Krutz et al., 2009; Vasconcellos et al., 2012).

A hipótese do trabalho é que existem espécies vegetais cultivadas no inverno que apresentam potencial de fitorremediar solos contaminados com os herbicidas atrazine e chlorimuron-ethyl + sulfometuron-methyl, aplicados para o manejo de plantas daninhas infestantes da soja, milho e sorgo. Diante disso, objetivou-se com o trabalho, avaliar 
o potencial fitorremediador de espécies de inverno cultivadas em solos contaminados com atrazine e chlorimuron-ethyl + sulfumeturon-methyl.

\section{Material e métodos}

Os trabalhos foram conduzidos em casa de vegetação na Universidade Federal da Fronteira Sul (UFFS), Campus Erechim. Como substrato foi utilizado solo classificado como Latossolo Vermelho Aluminoférrico Distrófico húmico (EMBRAPA, 2013).

Foram instalados dois experimentos, cada um arranjado em esquema fatorial $5 \times 4$, em delineamento inteiramente casualizado, com três repetições, sendo o primeiro instalado com o herbicida atrazine e o segundo com o chlorimuron-ethyl + sulfometuron-methyl. O fator A foi constituído pelas espécies com potencial fitorremediador: ervilhaca (Vicia sativa), nabo (Raphanus sativus), centeio (Secale cereale), soja-preta (Glycine max) e capim-colonião (Panicum maximum cv. Áries). Todas essas espécies foram escolhidas por apresentarem importância agrícola para o Rio Grande do Sul, onde são utilizadas como pastagens, cobertura do solo ou para a produção de grãos. No fator $\mathrm{B}$ foram alocadas as doses dos herbicidas atrazine $\left(0,0 ; 2,5 ; 5,0\right.$ e $\left.10,0 \mathrm{~L} \mathrm{ha}^{-1}\right)$ e chlorimuron-ethyl + sulfometuron-methyl $\left(0,0 ; 0,05 ; 0,100\right.$ e $\left.0,200 \mathrm{~kg} \mathrm{ha}^{-1}\right)$ marcas comerciais Proof $^{\circledR}$ e Ligate ${ }^{\circledR}$ respectivamente, aplicados em pré-emergência das culturas. Essas doses aplicadas representam: sem herbicida (0x), meia dose $(1 / 2 x)$, dose recomendada (1x) e o dobro da dose recomendada $(2 \mathrm{x})$.

As espécies fitorremediadoras foram cultivadas em vaso de polietileno (volume de $8 \mathrm{dm}^{3}$ ) preenchidos com solo, coletado em profundidade de 0-20 cm, em área sem histórico de aplicação de herbicidas, peneirado com malha de $4 \mathrm{~mm}$ e caracterizado físico e quimicamente.

Após o preenchimento dos vasos, foram aplicados os herbicidas atrazine e chlorimuron-ethyl + sulfometuron-methyl, utilizando-se um pulverizador costal de precisão, pressurizado a $\mathrm{CO}_{2}$, equipado com duas pontas de pulverização tipo leque DG 110.02, sob pressão constante de $2,0 \mathrm{kgf} \mathrm{cm}^{-2}$ e velocidade de deslocamento de $3,6 \mathrm{~km} \mathrm{~h}^{-1}$, o que proporcionou a vazão de $150 \mathrm{~L} \mathrm{ha}^{-1}$ de calda herbicida.

A semeadura das espécies com potencial fitorremediador foi realizada um dia antes da aplicação dos herbicidas, sendo que após a germinação realizou-se o desbaste deixando duas plantas por vaso. Para o bom desenvolvimento das plantas, efetuou-se irrigação diariamente nas unidades experimentais, mantendo a umidade em torno de $80 \%$ da capacidade de campo.

Aos 40 dias após a emergência das plantas (DAE) foram avaliadas as variáveis: fitotoxicidade, altura e massa seca da parte aérea. A fitotoxicidade foi avaliada de forma visual por dois avaliadores, atribuindo-se notas de zero (ausência de injúria) e $100 \%$ (morte completa das plantas) de acordo com a metodologia da SBCPD (1995). Já a altura de planta foi aferida com régua graduada, medindo-se desde rente ao solo até o ápice das últimas folhas totalmente desenvolvidas e a massa seca da parte aérea foi determinada pela secagem em estufa de circulação forçada de ar a uma temperatura de $60 \pm 5^{\circ} \mathrm{C}$ até atingir massa constante.

A segunda etapa do experimento teve por finalidade a confirmação do potencial das espécies de cobertura fitorremediarem o solo contaminado com chlorimuron-ethyl + sulfometuron-methyl e atrazine. Para isso foram coletadas amostras de solo de cada vaso da etapa anterior, peneirando o mesmo, para retirada de materiais grosseiros, torrões e raízes, e colocado em vasos plásticos com capacidade para $0,5 \mathrm{dm}^{3}$. Após, foi efetuada a semeadura da espécie bioindicadora, na presença de atrazine e chlorimuron-ethyl + sulfometuron-methyl, pepino (Cucumis sativus, cultivar Pioneiro), distribuindo-se 10 sementes por unidade experimental. Posteriormente, a emergência das plantas da espécie bioindicadora realizou-se o desbaste deixando-se somente duas plantas por unidade experimental. 
Aos 7, 14, 21 e 28 dias após a emergência (DAE), foram avaliadas, visualmente a fitotoxicidade nas plantas de pepino, conforme metodologia descrita anteriormente. Aos 35 DAE foram avaliadas a altura das plantas e a massa seca da parte aérea da cultura bioindicadora, de acordo com as metodologias descritas para a primeira etapa.

Os dados foram submetidos à análise de variância, em sendo significativos ao fator quantitativo aplicou-se regressões e ao fator qualitativo o teste de Tukey. Todos os testes foram efetuados a $\mathrm{p}>0,05$.

\section{Resultados e discussão}

\section{Ensaio com espécies com potencial de fitorremediação}

Hove interação significativa para os fatores testados (herbicidas $\mathrm{x}$ doses) para todas as variáveis analisadas. Os resultados demonstram que os dois herbicidas independente da dose aplicada ocasionaram fitotoxicidade nas espécies (Figura 1).

$\mathrm{O}$ incremento da dose de chlorimuron-ethyl + sulfometuron-methyl ocasionou aumento na fitotoxicidade para as espécies, sendo que já na metade da dose recomendada $\left(0,05 \mathrm{~kg} \mathrm{ha}^{-1}\right) \mathrm{o}$ centeio apresentou cerca de $50 \%$ de fitotoxicidade e a soja-preta cerca de $60 \%$. A partir da dose recomendada todas as espécies avaliadas apresentaram fitotoxicidade próxima a $100 \%$ ao se aplicar o chlorimuron-ethyl + sulfometuron-methyl, ou seja, ocorreu a morte completa das plantas. Esse herbicida apresenta alta eficiência de controle tanto de mono como de dicotiledôneas, principalmente em pré-emergência das plantas daninhas (Osiecka e Minogue, 2012).

A aplicação de atrazine ocasionou elevados sintomas de fitotoxicidade para todas as espécies testadas, exceto para o capim-colonião que apresentou fitotoxicidade de 15 e $25 \%$ com o uso de meia dose e da dose recomendada (2,5 e 5,0 $\left.\mathrm{L} \mathrm{ha}^{-1}\right)$, respectivamente (Figura 1). A aplicação do dobro da dose recomendada ocasionou a morte de todas as espécies testadas ou fitotoxicidade próxima a 100\%. Hawton (1980), observou que o $P$. maximum apresenta tolelância a atrazine até a dose de $2,5 \mathrm{~kg} \mathrm{ha}^{-1}$, justificando assim, a baixa fitotoxicidade até o tratamento com a dose recomendada.
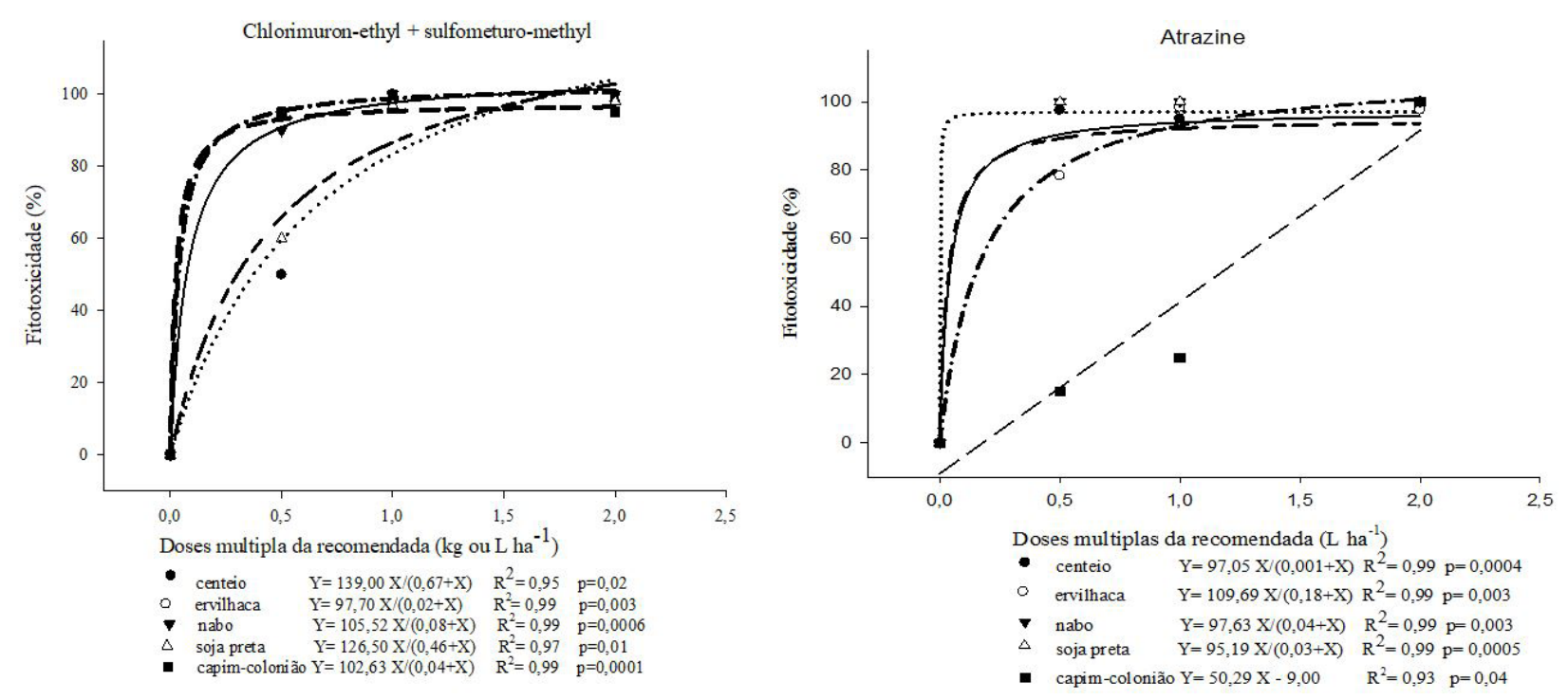

Figura 1. Fitotoxicidade ocasionada por doses múltiplas da recomendada dos herbicidas chlorimuron-ethyl + sulfometuron-methyl e atrazine sobre as culturas do centeio (•), ervilhaca (०), nabo $(\boldsymbol{\nabla})$, soja-preta $(\Delta)$ e capim-colonião $(\boldsymbol{\square})$. 
O centeio e a soja-preta foram as espécies que apresentaram menor fitotoxicidade ao se aplicar a meia dose de chlorimuron-ethyl + sulfometuron-methyl em relação a mesma dose de atrazine. A ervilhaca, entretanto, apresentou menor fitotoxicidade com uso de meia dose do herbicida atrazine quando comparada a meia dose de chlorimuron-ethyl + sulfometuron-methyl (Tabela 1). A ervilhaca já foi objeto de estudo como espécie com potencial de fitorremediação de herbicidas, sendo que quando submetida a aplicação de imazapic + imazapyr apresentou baixa fitotoxicidade (Galon et al., 2014), ressaltando-se que esses herbicidas pertencem ao mesmo mecanismo de ação.

O capim-colonião dentre os dois herbicidas testados apresentou menor fitoxicidade com aplicação de atrazine até a dose recomendada, já o uso do dobro da dose ocasionou a morte da espécie. O uso da dose recomendada ou o dobro da dose dos dois herbicidas não se observou diferenças significaticas entre eles, para todas as espécies. Exceto para capim-colonião que apresentou $25 \%$ de fitotoxicidade com uso da dose recomendada de atrazine, enquanto que a mistura de chlorimuron-ethyl + sulfometuron-methyl apresentou $100 \%$ (Tabela 1 ).

A altura de todas as espécies foi afetada pela aplicação dos herbicidas, sendo que as plantas de centeio, ervilhaca e soja-preta apresentaram redução aproximada de $50 \%$ ao se aplicar $0,05 \mathrm{~kg} \mathrm{ha}^{-1} \mathrm{de}$ chlorimuron-ethyl + sulfometuron-methyl, quando comparadas a testemunha sem aplicação. A altura do capim-colonião apresentou decréscimo ao se aplicar 2,5 e 5,0 L ha-1 de atrazine, ou seja, com o incremento da dose a altura das plantas reduziu linearmente (Figura 2). Esse decréscimo da altura

Tabela 1. Porcentagem de fitotoxicidade das espécies vegetais submetidas a aplicação de doses de chlorimuron-ethyl + sulfometuron-methyl e atrazine em pré-emergência.

\begin{tabular}{|c|c|c|c|}
\hline \multirow[b]{2}{*}{ Espécies } & \multicolumn{3}{|c|}{ Herbicidas } \\
\hline & $\begin{array}{c}\text { Dose múltipla da recomendada } \\
\left(\text { (kg ou } \mathrm{L} \mathrm{ha}^{-1}\right)\end{array}$ & Chlorimuron-ethyl + sulfometuron-methyl & Atrazine \\
\hline \multirow[t]{4}{*}{ Centeio } & 0 & $0,0 \mathrm{~A}^{1}$ & $0,0 \mathrm{~A}$ \\
\hline & $1 / 2$ & $50,0 \mathrm{~B}$ & $97,5 \mathrm{~A}$ \\
\hline & 1 & $99,0 \mathrm{~A}$ & $95,0 \mathrm{~A}$ \\
\hline & 2 & $98,0 \mathrm{~A}$ & $98,3 \mathrm{~A}$ \\
\hline \multirow{4}{*}{ Ervilhaca } & 0 & $0,0 \mathrm{~A}$ & $0,0 \mathrm{~A}$ \\
\hline & $1 / 2$ & $95,0 \mathrm{~A}$ & $78,3 \mathrm{~B}$ \\
\hline & 1 & $100,0 \mathrm{~A}$ & $98,3 \mathrm{~A}$ \\
\hline & 2 & $100,0 \mathrm{~A}$ & $97,7 \mathrm{~A}$ \\
\hline \multirow[t]{4}{*}{ Nabo } & 0 & $0,0 \mathrm{~A}$ & $0,0 \mathrm{~A}$ \\
\hline & $1 / 2$ & $100,0 \mathrm{~A}$ & $100,0 \mathrm{~A}$ \\
\hline & 1 & $100,0 \mathrm{~A}$ & $100,0 \mathrm{~A}$ \\
\hline & 2 & $100,0 \mathrm{~A}$ & $100,0 \mathrm{~A}$ \\
\hline \multirow[t]{4}{*}{ Soja-preta } & 0 & $0,0 \mathrm{~A}$ & $0,0 \mathrm{~A}$ \\
\hline & $1 / 2$ & $60,0 \mathrm{~B}$ & $100,0 \mathrm{~A}$ \\
\hline & 1 & $97,3 \mathrm{~A}$ & $100,0 \mathrm{~A}$ \\
\hline & 2 & $98,0 \mathrm{~A}$ & $100,0 \mathrm{~A}$ \\
\hline \multirow[t]{6}{*}{ Capim-colonião } & 0 & $0,0 \mathrm{~A}$ & $0,0 \mathrm{~A}$ \\
\hline & $1 / 2$ & $100,0 \mathrm{~A}$ & $15,0 \mathrm{~B}$ \\
\hline & 1 & $100,0 \mathrm{~A}$ & $25,0 \mathrm{~B}$ \\
\hline & 2 & $100,0 \mathrm{~A}$ & $100,0 \mathrm{~A}$ \\
\hline & Média Geral & 67,56 & \\
\hline & C.V & 3,90 & \\
\hline
\end{tabular}

${ }^{1}$ Médias seguidas de mesmas letras maiúsculas na linha não diferem entre si pelo teste de Tukey a p $>0,05$. 
está diretamente relacionado com a fitotoxicidade dos herbicidas, pois, plantas de girassol submetidas a aplicação de chlorimuron-ethyl apresentaram fitotoxicidade de $71 \%$ na avaliação dos 25 dias após a aplicação, reduzindo cerca de $73 \mathrm{~cm}$ em comparação a testemunha sem aplicação (Reis et al., 2014).

A dose recomendada e no dobro da dose de atrazine o centeio e a ervilhaca demonstraram valores superiores de altura quando comparados ao herbicida chlorimuron-ethyl + sulfometuronmethyl nas mesmas doses (Tabela 2). A soja-preta apresentou altura superior independente da dose do herbicida chlorimuron-ethyl + sulfometuron-methyl quando comparado a atrazine. Para o capim-colonião, independente da dose, a atrazine apresentou altura superior quando comparado ao herbicida chlorimuron-ethyl + sulfometuron-methyl (Tabela 2). Portanto, as espécies respondem de maneira diferenciada a aplicação dos herbicidas, sendo esse fato ligado, diretamente, a dose do herbicida, a fitotoxicidade ocasionada por eles nas plantas e também as caracaterísticas genéticas que cada espécie apresenta de tolerar mais ou menos os produtos.

A massa seca da parte aérea do centeio apresentou redução de $50 \%$ ao se aplicar $0,05 \mathrm{~kg} \mathrm{ha}^{-1}$ de chlorimuron-ethyl + sulfometuron-methyl. Para a atrazine o centeio demonstrou o menor acúmulo de massa seca da parte aérea com o incremento da dose, chegando a ser superior a 90\% de redução ao se aplicar 5,0 L ha-1 (Figura 3).

Para a soja-preta a redução aproximada de massa seca da parte aérea foi de $80 \%$, independente da dose de chlorimuron-ethyl + sulfometuron-methyl utilizada (Figura 3). Foi a única espécie que com as maiores doses não ocasinando a morte total das plantas (Tabela 3). Na cultura da soja, a fitotoxicidade proporcionada pela aplicação de sulfometuron-methyl foi superior a $60 \%$ a partir dos 21 dias após a aplicação, podendo chegar à

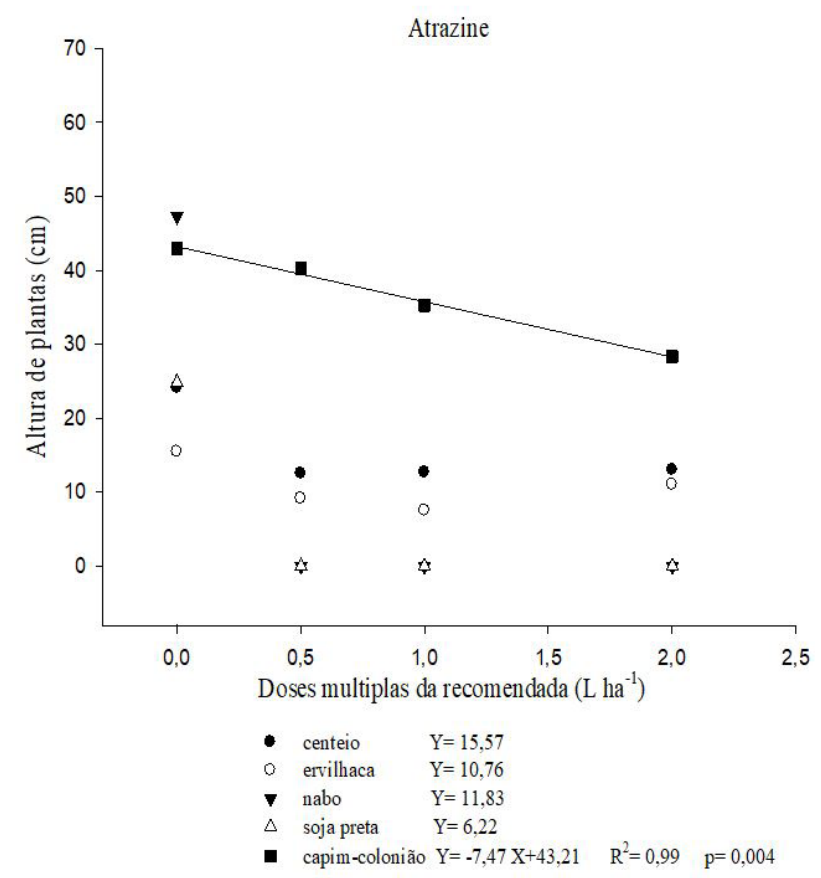

Figura 2. Altura de plantas $(\mathrm{cm})$ ocasionadas por doses múltiplas da recomendada dos herbicidas chlorimuron-ethyl + sulfometuron-methyl e atrazine sobre as culturas do centeio (•), ervilhaca (०), nabo $(\boldsymbol{\nabla})$, soja-preta $(\Delta)$ e capim-colonião $(\boldsymbol{\square})$. 

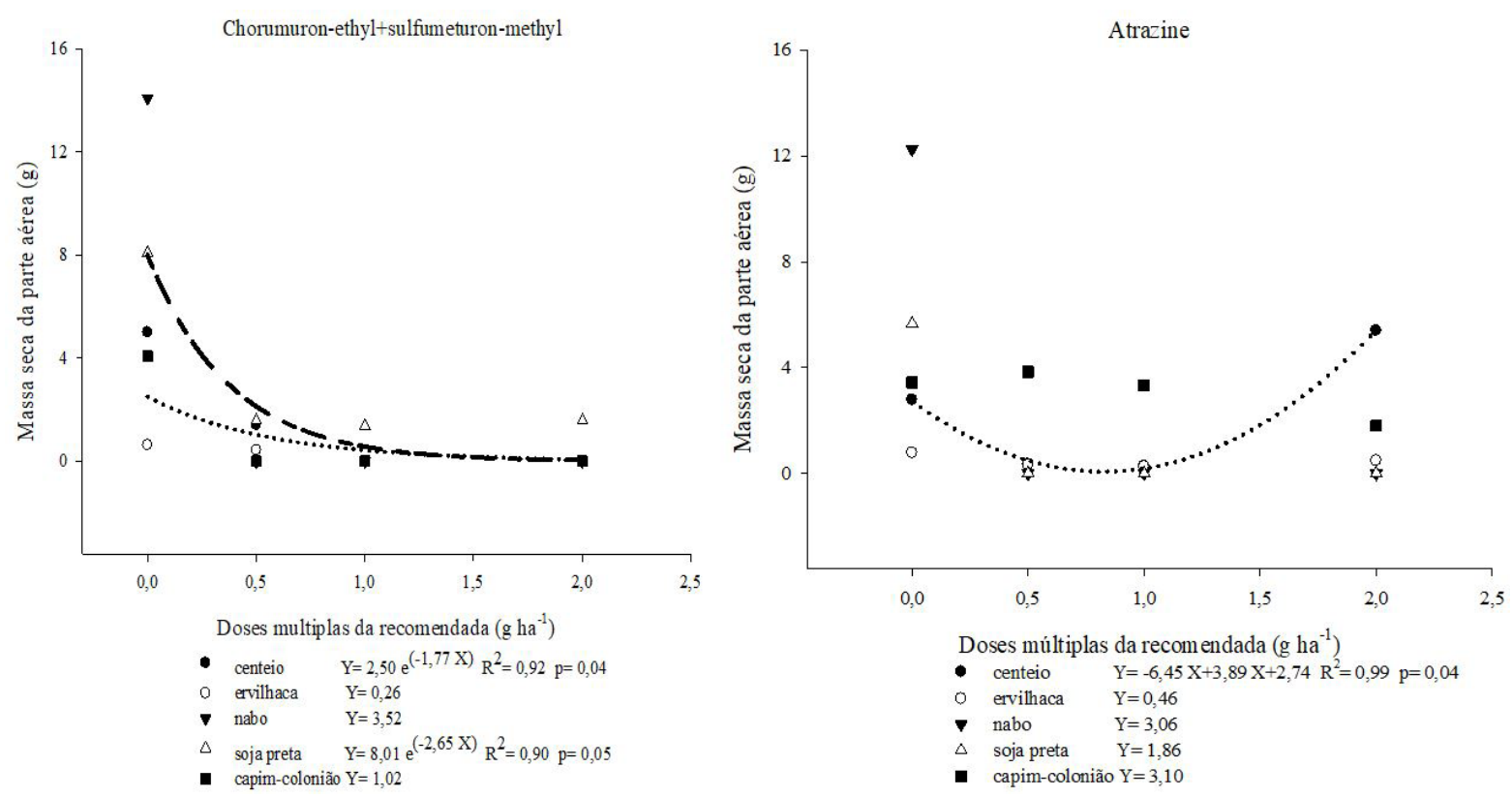

Figura 3. Massa seca da parte aérea (g) de plantas em função da aplicação de doses múltiplas da recomendada dos herbicidas chlorimuron-ethyl + sulfometuron-methyl e atrazine sobre as culturas do centeio $(\bullet)$, ervilhaca $(\circ)$, nabo $(\boldsymbol{\nabla})$, soja-preta $(\Delta)$ e capim-colonião $(\boldsymbol{\square})$.

Tabela 2. Altura de plantas $(\mathrm{cm})$ das espécies vegetais submetidas a aplicação de doses de chlorimuron-ethyl + sulfometuron-methyl e atrazine em pré-emergência.

\begin{tabular}{|c|c|c|c|}
\hline \multirow[b]{2}{*}{ Espécies } & \multicolumn{3}{|c|}{ Herbicidas } \\
\hline & 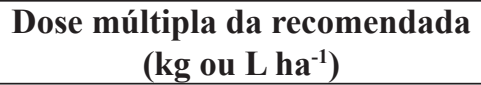 & Chlorimuron-ethyl + sulfometuron-methyl & Atrazine \\
\hline \multirow[t]{4}{*}{ Centeio } & 0 & $22,4 \mathrm{~A}^{1}$ & $24,1 \mathrm{~A}$ \\
\hline & $1 / 2$ & $14,3 \mathrm{~A}$ & $12,5 \mathrm{~A}$ \\
\hline & 1 & $0,0 \mathrm{~B}$ & $12,7 \mathrm{~A}$ \\
\hline & 2 & $0,0 \mathrm{~B}$ & $13,0 \mathrm{~A}$ \\
\hline \multirow[t]{4}{*}{ Ervilhaca } & 0 & $14,1 \mathrm{~A}$ & $15,4 \mathrm{~A}$ \\
\hline & $1 / 2$ & $7,3 \mathrm{~A}$ & $9,1 \mathrm{~A}$ \\
\hline & 1 & $0,0 \mathrm{~B}$ & $7,5 \mathrm{~A}$ \\
\hline & 2 & $0,0 \mathrm{~B}$ & $11,0 \mathrm{~A}$ \\
\hline \multirow[t]{4}{*}{ Nabo } & 0 & $57,7 \mathrm{~A}$ & $57,3 \mathrm{~A}$ \\
\hline & $1 / 2$ & $0,0 \mathrm{~A}$ & $0,0 \mathrm{~A}$ \\
\hline & 1 & $0,0 \mathrm{~A}$ & $0,0 \mathrm{~A}$ \\
\hline & 2 & $0,0 \mathrm{~A}$ & $0,0 \mathrm{~A}$ \\
\hline \multirow[t]{4}{*}{ Soja-preta } & 0 & $26,0 \mathrm{~A}$ & $24,9 \mathrm{~A}$ \\
\hline & $1 / 2$ & $11,6 \mathrm{~A}$ & $0,0 \mathrm{~B}$ \\
\hline & 1 & $2,7 \mathrm{~A}$ & $0,0 \mathrm{~A}$ \\
\hline & 2 & $5,2 \mathrm{~A}$ & $0,0 \mathrm{~B}$ \\
\hline \multirow[t]{6}{*}{ Capim-colonião } & 0 & $45,1 \mathrm{~A}$ & $42,9 \mathrm{~A}$ \\
\hline & $1 / 2$ & $0,0 \mathrm{~B}$ & $40,2 \mathrm{~A}$ \\
\hline & 1 & $0,0 \mathrm{~B}$ & $35,3 \mathrm{~A}$ \\
\hline & 2 & $0,0 \mathrm{~B}$ & $28,3 \mathrm{~A}$ \\
\hline & Média Geral & 13,27 & \\
\hline & C.V & 16,15 & \\
\hline
\end{tabular}

${ }^{1}$ Médias seguidas de mesmas letras maiúsculas na linha não diferem entre si pelo teste de Tukey a p $>0,05$. 
Tabela 3. Massa seca da parte aérea das espécies vegetais submetidas a aplicação de doses de chlorimuron-ethyl + sulfometuron-methyl e atrazine em pré-emergência.

\begin{tabular}{|c|c|c|c|}
\hline \multirow[b]{2}{*}{ Espécies } & \multicolumn{3}{|c|}{ Herbicidas } \\
\hline & $\begin{array}{c}\text { Dose múltipla da recomendada } \\
\left(\mathrm{kg} \mathrm{ou} \mathrm{L} \mathrm{ha-1)}^{-1}\right)\end{array}$ & Chlorimuron-ethyl+sulfometuron-methyl & Atrazine \\
\hline \multirow[t]{4}{*}{ Centeio } & 0 & $5,0 \mathrm{~B}^{1}$ & $5,4 \mathrm{~A}$ \\
\hline & $1 / 2$ & $1,4 \mathrm{~B}$ & $2,8 \mathrm{~A}$ \\
\hline & 1 & $0,0 \mathrm{~A}$ & $0,4 \mathrm{~A}$ \\
\hline & 2 & $0,0 \mathrm{~A}$ & $0,3 \mathrm{~A}$ \\
\hline \multirow[t]{4}{*}{ Ervilhaca } & 0 & $0,6 \mathrm{~A}$ & $0,8 \mathrm{~A}$ \\
\hline & $1 / 2$ & $0,4 \mathrm{~A}$ & $0,3 \mathrm{~A}$ \\
\hline & 1 & $0,0 \mathrm{~A}$ & $0,3 \mathrm{~A}$ \\
\hline & 2 & $0,0 \mathrm{~A}$ & $0,5 \mathrm{~A}$ \\
\hline \multirow[t]{4}{*}{ Nabo } & 0 & $14,0 \mathrm{~A}$ & $12,2 \mathrm{~A}$ \\
\hline & $1 / 2$ & $0,0 \mathrm{~A}$ & $0,0 \mathrm{~A}$ \\
\hline & 1 & $0,0 \mathrm{~A}$ & $0,0 \mathrm{~A}$ \\
\hline & 2 & $0,0 \mathrm{~A}$ & $0,0 \mathrm{~A}$ \\
\hline \multirow[t]{4}{*}{ Soja-preta } & 0 & $8,1 \mathrm{~A}$ & $7,5 \mathrm{~A}$ \\
\hline & $1 / 2$ & $1,6 \mathrm{~A}$ & $0,0 \mathrm{~B}$ \\
\hline & 1 & $1,4 \mathrm{~A}$ & $0,0 \mathrm{~B}$ \\
\hline & 2 & $1,6 \mathrm{~A}$ & $0,0 \mathrm{~B}$ \\
\hline \multirow[t]{6}{*}{ Capim-colonião } & 0 & $4,1 \mathrm{~A}$ & $3,4 \mathrm{~A}$ \\
\hline & $1 / 2$ & $0,0 \mathrm{~B}$ & $3,8 \mathrm{~A}$ \\
\hline & 1 & $0,0 \mathrm{~B}$ & $3,3 \mathrm{~A}$ \\
\hline & 2 & $0,0 \mathrm{~B}$ & $1,8 \mathrm{~A}$ \\
\hline & Média Geral & 1,92 & \\
\hline & C.V & 21,22 & \\
\hline
\end{tabular}

${ }^{1}$ Médias seguidas de mesmas letras maiúsculas na linha não diferem entre si pelo teste de Tukey a p>0,05.

96\% nos 37 dias, mesmo assim não ocasionando a morte total das plantas (Correia e Leite, 2012).

O uso de chlorimuron-ethyl + sulfometuron-methyl e atrazine sobre a ervilhaca não apresentou variação de massa seca da parte aérea, independente da dose aplicada de ambos os herbicidas (Figura 3). Não somente com esse herbicida, mas com a aplicação da mistura de imazapic + imazapyr em trabalho conduzido por Galon et al. (2014), destaca-se a ervilhaca com potencial de fitorremediação de solo contaminado pelos produtos.

Pode-se observar que o capim-colonião não demonstrou variação de massa seca ao se aplicar as doses de 0,0; 2,5 e 5,0 $\mathrm{L} \mathrm{ha}^{-1}$ de atrazine, com média de produção de massa seca da parte aérea de 3,10 g (Figura 3). Quando se compara os herbicidas nas diferentes doses, percebe-se que ao se aplicar o atrazine sobre o capim-colonião ocorre maior produção de massa seca da parte aérea ao se comparar com o uso de chlorimuron-ethyl + sulfometuron-methyl, o qual na dose mais baixa apresentou a morte das plantas (Tabela 3). Hawton (1980) já relatou que o capim-colonião apresenta tolerância ao atrazine, isso explica a maior produção de massa seca da parte aérea do presente estudo quando se aplica esse herbicida sobre a planta.

\section{Ensaio com espécie bioindicadora - pepino}

A fitotoxicidade ocasionada pelo herbicida chlorimuron-ethyl + sulfometuron-methyl ao pepino foi relativamente baixa na avaliação inicial, aos 07 dias após a emergência (DAE), com valores máximos de 30\% (Figura 4A). $\mathrm{Na}$ avaliação dos 14 e $21 \mathrm{DAE}$, percebeu-se um aumento expressivo na fitotoxicidade, acima de 

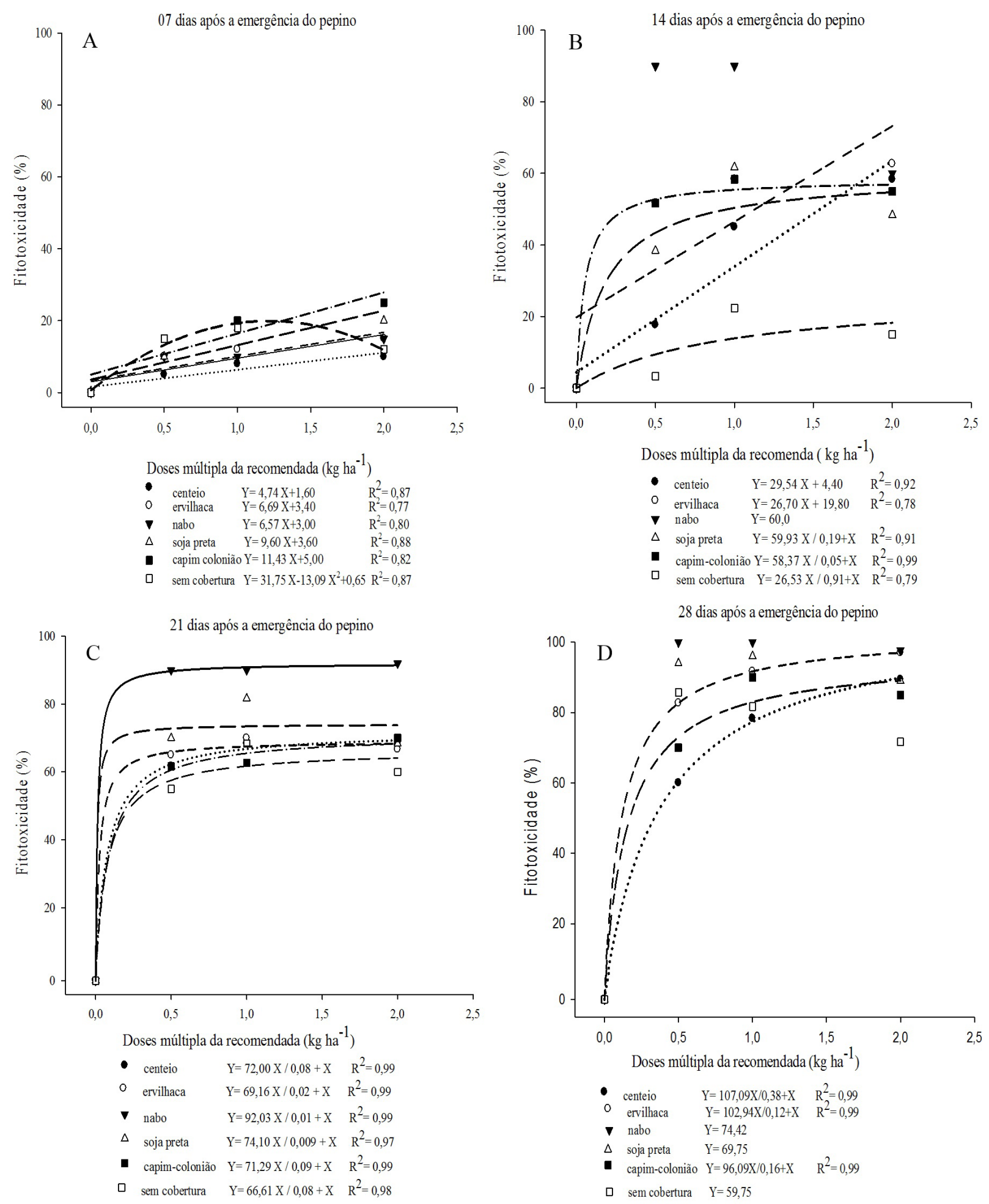

Figura 4. Fitotoxicidade (\%) à cultura do pepino aos 7 (A), 14 (B), 21 (C) e 28 (D) dias após a emergência em função da aplicação de doses múltiplas da recomendada do herbicida chlorimuron-ethyl + sulfometuron-methyl após a fitorremediação do solo com as coberturas; centeio (•), ervilhaca (०), nabo ( $\boldsymbol{\nabla})$, soja-preta $(\Delta)$, capim-colonião $(\boldsymbol{\square})$ e sem cobertura $(\square)$. 
$50 \%$, exceto para o tratamento sem planta aos 14 DAE (Figura 4B e C).

De maneira geral, o tratamento que não havia coberturas de solo (sem plantas) foi o que apresentou os menores sintomas de fitotoxicidade sobre o pepino, porém, aos $28 \mathrm{DAE}$, os valores médios de fitotoxicidade foram de $80 \%$, considerados altos. Esse fato possivelmente ocorreu por uma maior fotodegradação dos herbicidas no solo, mas que merece um estudo mais aprofundado. O sulfometuron-methyl é muito utilizado no controle de plantas daninhas em cultivos de cana-de-açúcar e mais recentemente vem sendo avaliado em soja que apresentam tolerância ao produto, porém extremamente fitotóxico a cultivares que não apresentam essa tecnologia ou a tolerância a esse herbicida (Osiecka e Minogue, 2012; Correia e Leite, 2012).

$\mathrm{Na}$ dose recomendada e na metade da dose do chlorimuron-ethyl + sulfometuron-methyl, observou-se que o uso do centeio como espécie com potencial fitorremediador foi o que proporcionou as menores fitotoxicidade ao pepino, ao se comparar com as demais espécies. E dentre todas as espécies testadas o nabo apresentou os piores resultados como planta fitorremediadora de solos contaminados com os herbicidas chlorimuron-ethyl + sulfometuron-methyl (Tabela 4). Muito embora as espécies vegetais são extremamente importantes na fitorremediação de solos, novas técnicas utlizando

Tabela 4. Fitotoxicidade (\%) de chlorimuron + sulfumeturon-methyl sobre o pepino usado como espécie bioindicadora de solo fitorremediado por centeio, ervilhaca, nabo, soja-preta, capim-colonião e sem cobertura após a aplicação de doses do herbicida.

\begin{tabular}{|c|c|c|c|c|c|}
\hline \multirow{2}{*}{$\begin{array}{l}\text { Dose múltipla da } \\
\text { recomendada }\left(\mathrm{kg} \text { ou } \mathrm{L} \mathrm{ha}^{-1}\right)\end{array}$} & \multirow{2}{*}{ Espécies } & \multicolumn{4}{|c|}{ Fitotoxicidade (\%) ao pepino } \\
\hline & & 07 DAT ${ }^{1}$ & 14 DAT & 21 DAT & 28 DAT \\
\hline \multirow[t]{6}{*}{0} & Centeio & $0,0 \mathrm{a}^{2}$ & $0,0 \mathrm{a}$ & $0,0 \mathrm{a}$ & $0,0 \mathrm{a}$ \\
\hline & Ervilhaca & $0,0 \mathrm{a}$ & $0,0 \mathrm{a}$ & $0,0 \mathrm{a}$ & $0,0 \mathrm{a}$ \\
\hline & Nabo & $0,0 \mathrm{a}$ & $0,0 \mathrm{a}$ & $0,0 \mathrm{a}$ & $0,0 \mathrm{a}$ \\
\hline & Soja-preta & $0,0 \mathrm{a}$ & $0,0 \mathrm{a}$ & $0,0 \mathrm{a}$ & $0,0 \mathrm{a}$ \\
\hline & Capim-colonião & $0,0 \mathrm{a}$ & $0,0 \mathrm{a}$ & $0,0 \mathrm{a}$ & $0,0 \mathrm{a}$ \\
\hline & Sem cobertura & $0,0 \mathrm{a}$ & $0,0 \mathrm{a}$ & $0,0 \mathrm{a}$ & $0,0 \mathrm{a}$ \\
\hline \multirow[t]{6}{*}{$1 / 2$} & Centeio & $5,0 \mathrm{c}$ & $17,7 \mathrm{~d}$ & $61,7 \mathrm{bc}$ & $60,0 \mathrm{~d}$ \\
\hline & Ervilhaca & $10,0 \mathrm{~b}$ & $51,7 \mathrm{~b}$ & $65,0 \mathrm{bc}$ & $82,7 \mathrm{c}$ \\
\hline & Nabo & $10,0 \mathrm{~b}$ & $90,0 \mathrm{a}$ & $90,0 \mathrm{a}$ & $100,0 \mathrm{a}$ \\
\hline & Soja-preta & $10,0 \mathrm{~b}$ & $38,3 \mathrm{c}$ & $70,0 \mathrm{~b}$ & $94,0 \mathrm{ab}$ \\
\hline & Capim-colonião & $15,0 \mathrm{a}$ & $51,7 \mathrm{~b}$ & $62,7 \mathrm{c}$ & $70,0 \mathrm{~d}$ \\
\hline & Sem cobertura & $15,0 \mathrm{a}$ & $31,0 \mathrm{~cd}$ & $55,0 \mathrm{c}$ & $85,7 \mathrm{bc}$ \\
\hline \multirow[t]{6}{*}{1} & Centeio & $8,0 \mathrm{e}$ & $45,0 \mathrm{c}$ & $68,3 \mathrm{bc}$ & $78,3 \mathrm{c}$ \\
\hline & Ervilhaca & $12,0 \mathrm{c}$ & $58,3 \mathrm{bc}$ & $70,0 \mathrm{bc}$ & $91,7 \mathrm{ab}$ \\
\hline & Nabo & $10,0 \mathrm{~d}$ & $90,0 \mathrm{a}$ & $90,0 \mathrm{a}$ & $100,0 \mathrm{a}$ \\
\hline & Soja-preta & $18,0 \mathrm{~b}$ & $61,7 \mathrm{~b}$ & $81,7 \mathrm{ab}$ & $96,0 \mathrm{a}$ \\
\hline & Capim-colonião & $20,0 \mathrm{a}$ & $58,3 \mathrm{c}$ & $62,7 \mathrm{c}$ & $90,0 \mathrm{ab}$ \\
\hline & Sem cobertura & $18,0 \mathrm{~b}$ & $45,0 \mathrm{c}$ & $68,3 \mathrm{bc}$ & $81,7 \mathrm{bc}$ \\
\hline \multirow[t]{6}{*}{2} & Centeio & $10,0 \mathrm{e}$ & $58,3 \mathrm{ab}$ & $68,3 \mathrm{~b}$ & $89,3 \mathrm{ab}$ \\
\hline & Ervilhaca & $15,0 \mathrm{c}$ & $62,7 \mathrm{a}$ & $66,7 \mathrm{~b}$ & $97,0 \mathrm{a}$ \\
\hline & Nabo & $15,0 \mathrm{c}$ & $60,0 \mathrm{ab}$ & $92,0 \mathrm{a}$ & $97,7 \mathrm{a}$ \\
\hline & Soja-preta & $20,0 \mathrm{~b}$ & $48,3 \mathrm{bc}$ & $68,3 \mathrm{~b}$ & $89,0 \mathrm{ab}$ \\
\hline & Capim-colonião & $25,0 \mathrm{a}$ & $55,0 \mathrm{ab}$ & $70,0 \mathrm{~b}$ & $85,0 \mathrm{~b}$ \\
\hline & Sem cobertura & $12,0 \mathrm{~d}$ & $38,3 \mathrm{c}$ & $60,0 \mathrm{~b}$ & $72,7 \mathrm{c}$ \\
\hline \multicolumn{2}{|c|}{ Média Geral } & 10,47 & 40,08 & 52,90 & 65,01 \\
\hline \multicolumn{2}{|c|}{ C.V. (\%) } & 1,57 & 14,58 & 11,06 & 6,95 \\
\hline
\end{tabular}

${ }^{1}$ Dias após a aplicação dos tratamentos. ${ }^{2}$ Médias seguidas de mesmas letras minúsculas na coluna, para cada dose dos herbicidas, não diferem entre si pelo teste de Tukey a $\mathrm{p}>0,05$. 
consórcios bacterianos estão sendo desenvolvidas para biorremediação de solos contaminados com chlorimuron-ethyl, principalmente pela eficiência e rapidez no crescimento de microrganismos (Li et al., 2017).

Com relação a atrazine, observou-se que aos 07 DAE somente o manejo sem cobertura apresentou efeito significativo, aumentando linearmente conforme o incremento da dose do herbicida, chegando a 5,2\% de fitotoxicidade no dobro da dose (Figura 5A). Já para a avaliação dos 14 DAE as espécies, capim-colonião e soja-preta, juntamente com o nabo, sem cobertura e centeio aos $21 \mathrm{DAE}$, foram as que menos fitorremediaram solo contaminado com atrazine (Figura $5 \mathrm{~B}$ e C, e Tabela 5). Merini et al. (2009), encontraram em Lolium multiflorum uma importante ferramenta para fitorremediação de solos contaminados com atrazine, sendo que isso muito se deve a desintoxicação enzimática via P450, a qual confere tolerância dessa espécie ao referido herbicida.

Na última avaliação de fitotoxicidade (28 DAE) dá-se destaque para as espécies de nabo, ervilhaca e centeio como potencialmente fitorremediadoras, pois, ocasionaram baixa ou nula fitotoxicidade as plantas de pepino, na dose recomenda e no

Tabela 5. Fitotoxicidade (\%) de atrazine sobre o pepino usado como espécie bioindicadora de solo fitorremediado por centeio, ervilhaca, nabo, soja-preta, capim-colonião e sem cobertura após a aplicação de doses do herbicida.

\begin{tabular}{|c|c|c|c|c|c|}
\hline \multirow{2}{*}{ 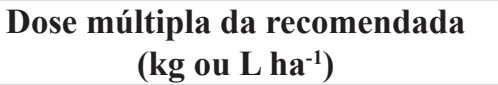 } & \multirow{2}{*}{ Espécies } & \multicolumn{4}{|c|}{ Fitotoxicidade (\%) ao pepino } \\
\hline & & 07 DAT $^{1}$ & 14 DAT & 21 DAT & 28 DAT \\
\hline \multirow[t]{6}{*}{0} & Centeio & $0,0 \mathrm{a}^{2}$ & $0,0 \mathrm{a}$ & $0,0 \mathrm{a}$ & $0,0 \mathrm{a}$ \\
\hline & Ervilhaca & $0,0 \mathrm{a}$ & $0,0 \mathrm{a}$ & $0,0 \mathrm{a}$ & $0,0 \mathrm{a}$ \\
\hline & Nabo & $0,0 \mathrm{a}$ & $0,0 \mathrm{a}$ & $0,0 \mathrm{a}$ & $0,0 \mathrm{a}$ \\
\hline & Soja-preta & $0,0 \mathrm{a}$ & $0,0 \mathrm{a}$ & $0,0 \mathrm{a}$ & $0,0 \mathrm{a}$ \\
\hline & Capim-colonião & $0,0 \mathrm{a}$ & $0,0 \mathrm{a}$ & $0,0 \mathrm{a}$ & $0,0 \mathrm{a}$ \\
\hline & Sem cobertura & $0,0 \mathrm{a}$ & $0,0 \mathrm{a}$ & $0,0 \mathrm{a}$ & $0,0 \mathrm{a}$ \\
\hline \multirow[t]{6}{*}{$1 / 2$} & Centeio & $0,0 \mathrm{c}$ & $3,3 \mathrm{~b}$ & $11,7 \mathrm{c}$ & $0,0 \mathrm{c}$ \\
\hline & Ervilhaca & $3,0 \mathrm{a}$ & $0,0 \mathrm{~b}$ & $23,3 \mathrm{ab}$ & $10,0 \mathrm{~b}$ \\
\hline & Nabo & $0,0 \mathrm{c}$ & $0,0 \mathrm{~b}$ & $13,3 \mathrm{bc}$ & $0,0 \mathrm{c}$ \\
\hline & Soja-preta & $0,0 \mathrm{c}$ & $0,0 \mathrm{~b}$ & $10,0 \mathrm{c}$ & $13,3 \mathrm{~b}$ \\
\hline & Capim-colonião & $0,0 \mathrm{c}$ & $0,0 \mathrm{~b}$ & $11,7 \mathrm{c}$ & $12,3 \mathrm{~b}$ \\
\hline & Sem cobertura & $2,0 \mathrm{~b}$ & $11,0 \mathrm{a}$ & $25,0 \mathrm{a}$ & $31,7 \mathrm{a}$ \\
\hline \multirow[t]{6}{*}{1} & Centeio & $2,0 \mathrm{~b}$ & $22,3 \mathrm{a}$ & $25,0 \mathrm{a}$ & $0,0 \mathrm{c}$ \\
\hline & Ervilhaca & $2,0 \mathrm{~b}$ & $0,0 \mathrm{c}$ & $4,3 \mathrm{~b}$ & $0,0 \mathrm{c}$ \\
\hline & Nabo & $0,0 \mathrm{c}$ & $5,0 \mathrm{bc}$ & $15,0 \mathrm{a}$ & $0,0 \mathrm{c}$ \\
\hline & Soja-preta & $0,0 \mathrm{c}$ & $0,0 \mathrm{c}$ & $15,7 \mathrm{a}$ & $11,0 \mathrm{~b}$ \\
\hline & Capim-colonião & $0,0 \mathrm{c}$ & $12,3 \mathrm{~b}$ & $22,3 \mathrm{a}$ & $25,0 \mathrm{a}$ \\
\hline & Sem cobertura & $3,0 \mathrm{a}$ & $5,3 \mathrm{bc}$ & $21,7 \mathrm{a}$ & $33,3 \mathrm{a}$ \\
\hline \multirow[t]{6}{*}{2} & Centeio & $2,0 \mathrm{~b}$ & $15,0 \mathrm{~b}$ & $27,3 \mathrm{ab}$ & $0,0 \mathrm{c}$ \\
\hline & Ervilhaca & $2,0 \mathrm{~b}$ & $2,3 \mathrm{c}$ & $17,7 \mathrm{bc}$ & $0,0 \mathrm{c}$ \\
\hline & Nabo & $0,0 \mathrm{c}$ & $4,3 \mathrm{c}$ & $28,3 \mathrm{a}$ & $0,0 \mathrm{c}$ \\
\hline & Soja-preta & $0,0 \mathrm{c}$ & $3,7 \mathrm{c}$ & $11,0 \mathrm{c}$ & $6,3 \mathrm{bc}$ \\
\hline & Capim-colonião & $0,0 \mathrm{c}$ & $28,3 \mathrm{a}$ & $25,7 \mathrm{ab}$ & $12,3 \mathrm{~b}$ \\
\hline & Sem cobertura & $5,0 \mathrm{a}$ & $12,3 \mathrm{~b}$ & $24,0 \mathrm{ab}$ & $26,7 \mathrm{a}$ \\
\hline Média Geral & & 1,08 & 5,36 & 13,96 & 7,75 \\
\hline C.V. $(\%)$ & & 26,36 & 58,47 & 30,52 & 47,35 \\
\hline
\end{tabular}

${ }^{1}$ Dias após a aplicação dos tratamentos. ${ }^{2}$ Médias seguidas de mesmas letras minúsculas na coluna, para cada dose dos herbicidas, não diferem entre si pelo teste de Tukey a $\mathrm{p}>0,05$. 

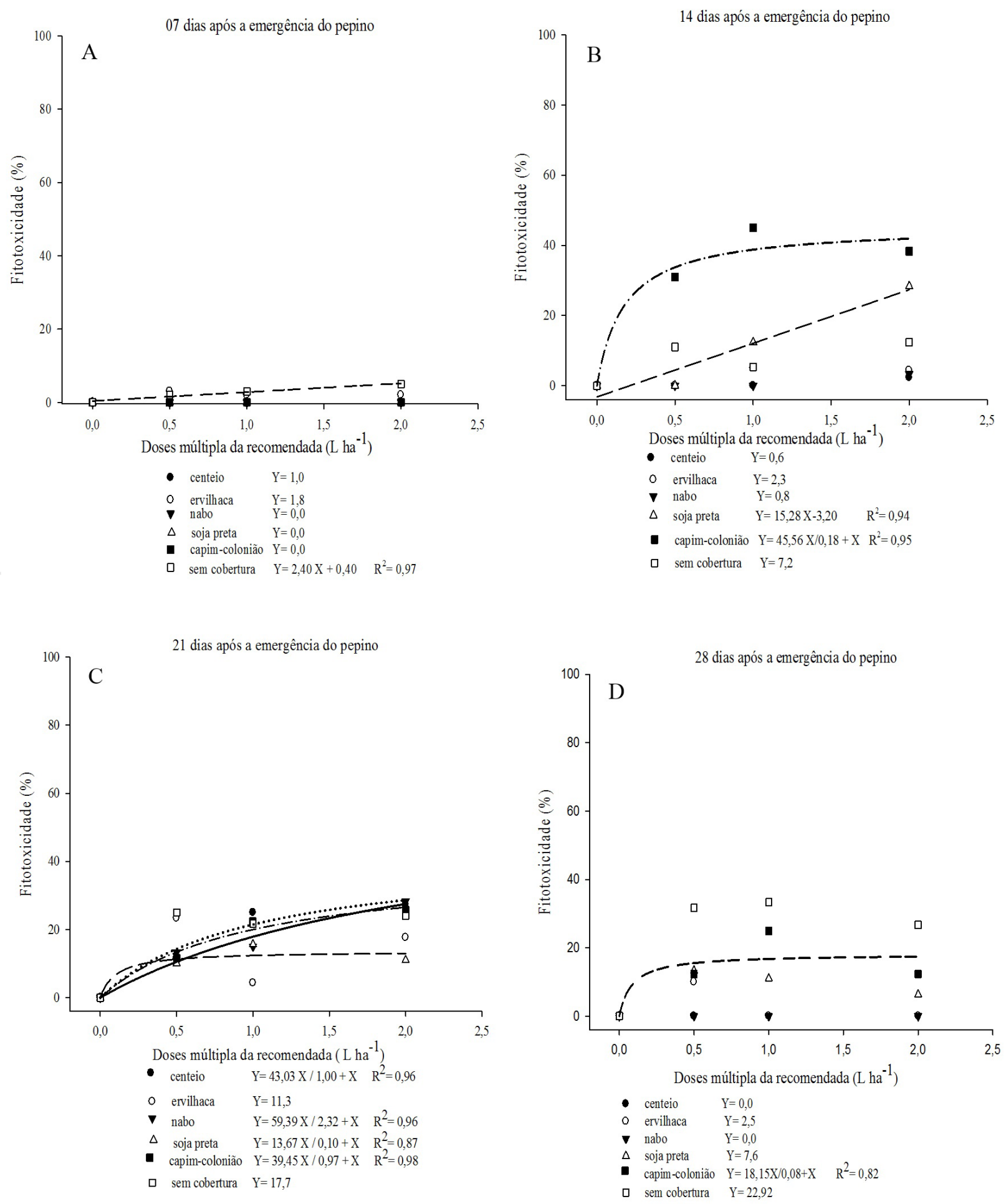

Figura 5. Fitotoxicidade (\%) à cultura do pepino aos 7 (A), 14 (B), 21 (C) e 28 (D) dias após a emergência em função da aplicação de doses múltiplas da recomendada do herbicida atrazine após a fitorremediação do solo com as coberturas; centeio $(\bullet)$, ervilhaca $(\circ)$, nabo $(\boldsymbol{\nabla})$, soja-preta $(\Delta)$, capim-colonião ( $\square)$ e sem cobertura $(\square)$. 
dobro da dose de atrazine. O pior desempenho de fitorremediação foi para o manejo sem cobertura (Figura 5D e Tabela 5). O que pode ser explicado pelo fato da atrazine apresentar alta absorção pelas raízes das plantas, e acumulação em seus órgãos, conforme o aumento de sua concentração no solo (Li et al., 2012) e desse modo ficou menos disponível ao pepino.

Observou-se que a altura de plantas de pepino foi severamente afetada com o aumento das doses de chlorimuron-ethyl + sulfometuron-methyl, para todas as espécies utilizadas como plantas com potencial fitorremediador de solo. Destaca-se, no entanto, que o solo mantido sem cobertura, por mais que houve redução de $40 \%$ ao se comparar o dobro da dose com a testemunha sem herbicida, foi o tratamento que apresentou menor redução da altura do pepino (Figura 6A). Esse fato possivelmente esteja ligado a degradação mais

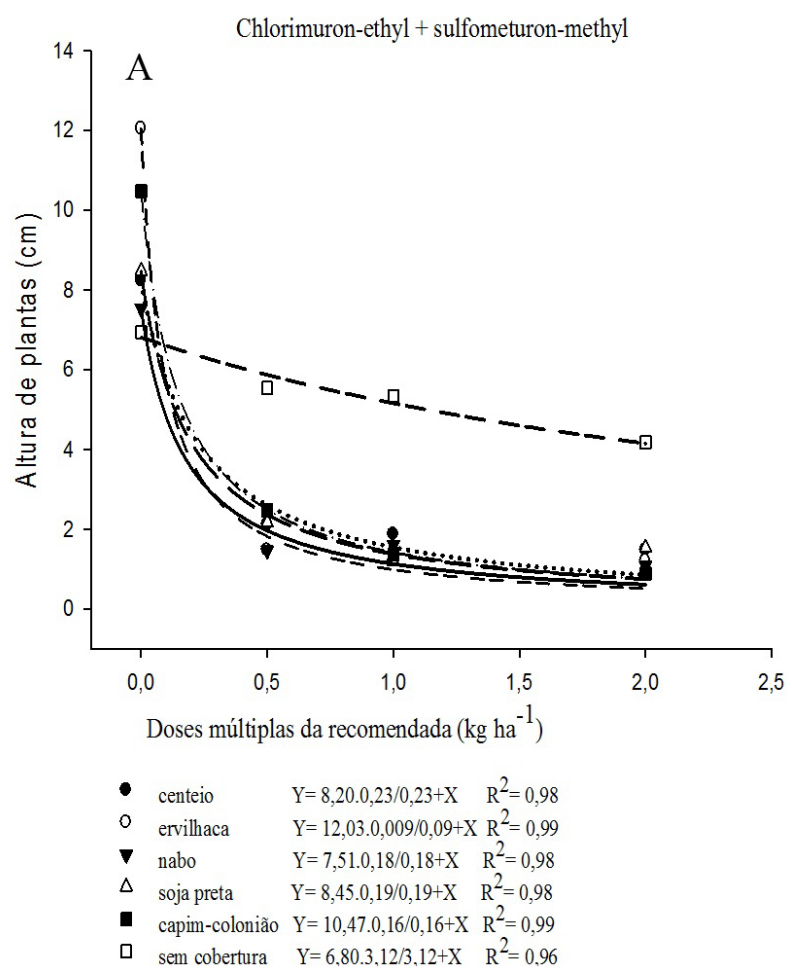

rápida dos herbicidas, decorrentes, da maior variação de temperatura, umidade e radiação solar que ocorreu nesse tratamento ao não se utilizar plantas em cobertura do solo. De acordo com Silva et al. (2007b) a radiação solar na faixa do ultravioleta apresenta energia suficiente ara causar transformações químicas dos herbicidas, as quais podem levar a sua inativação.

Em relação ao herbicida atrazine não houve ajuste dos dados aos modelos testados, para a altura de plantas do pepino para todas as espécies cultivadas anteriormente, exceto para o nabo que teve um aumento até a dose recomendada e decréscimo com o aumento para o dobro da dose (Figura 6B). A menor média geral de altura do pepino com base na Figura 6B foi obtida no tratamento sem cobertura com 7,85 cm. Ao se comparar o tratamento sem cobertura em relação aos demais na dose recomenda e no dobro da dose,

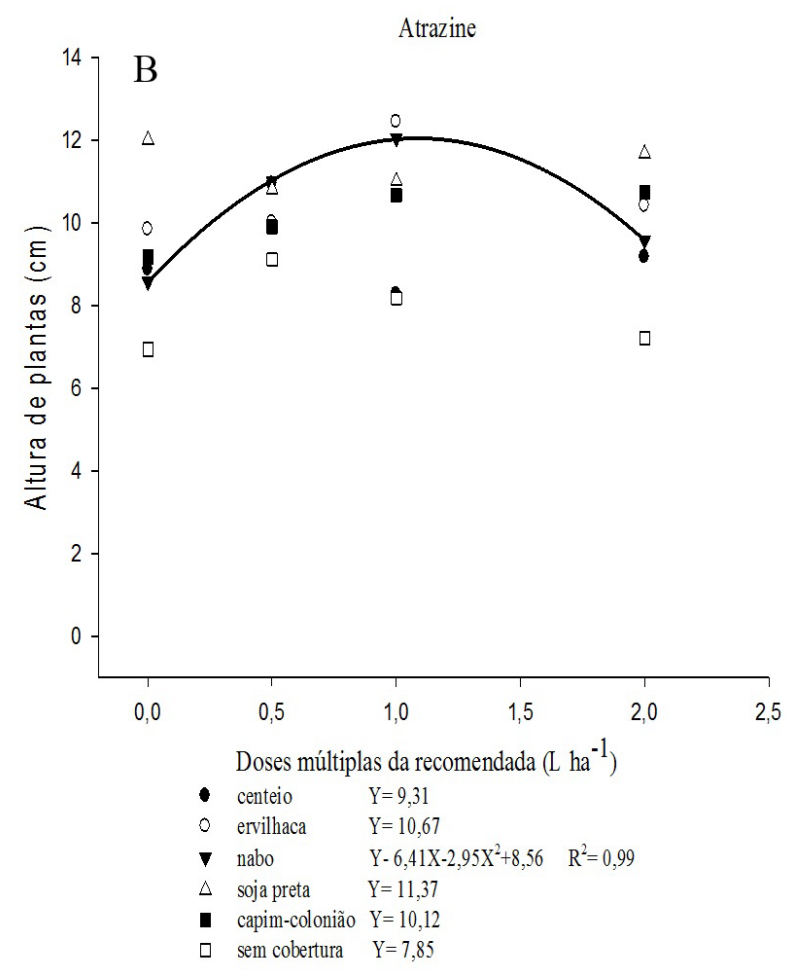

Figura 6. Altura de plantas $(\mathrm{cm})$ de pepino em função da aplicação de doses múltiplas da recomendada do herbicida chlorimuron-ethyl + sulfometuron-methyl (A) e de atrazine (B) após a fitorremediação do solo com as coberturas; centeio $(\bullet)$, ervilhaca $(\odot)$, nabo $(\boldsymbol{\nabla})$, soja-preta $(\Delta)$, capim-colonião (ם) e sem cobertura $(\square)$. 
observou-se que esse demonstra a menor altura de plantas (Tabela 6). Esse fato pode estar diretamente relacionado a absorção e acumulação da atrazine nas plantas (Li et al., 2012), o que não ocorreu no tratamento sem cobertura, ocasionando assim maiores fitotoxicidade (Tabela 5) e posteriormente redução de altura das plantas de pepino (Tabela 6).

Observou-se ao se comparar o uso de espécies fitorremediadoras, que quando o solo permaneceu sem cobertura (sem plantas), houve efeito positivo a cultura bioindicadora, ou seja, apresentou maior crescimento em todas as doses aplicadas de chlorimuron-ethyl + sulfometuron-methyl
(Tabela 6). A paralização do crescimento das plantas nos demais tratamentos onde havia cultivo de espécies fitorremediadoras, comparado com o tratamento sem cobertura, de acordo com Procópio et al. (2005) pode ser decorrente de um possível efeito alelopático das espécies sobre a cultura bioindicadora, no caso o pepino.

Os resultados demonstram que ao se aplicar o atrazine e após se cultivar espécies fitorremediadoras como a ervilhaca, nabo, soja-preta e capim colonião à um efeito positivo dessas espécies para fitorremediarem o solo. Desse modo, ocorreu fitorremediação do solo ao se aplicar o atrazine e

Tabela 6. Altura de plantas de pepino $(\mathrm{cm})$ usado como espécie bioindicadora de solo fitorremediado por centeio, ervilhaca, nabo, soja-preta, capim-colonião e sem cobertura após a aplicação de doses de chlorimuron + sulfumeturon-methyl e atrazine, respectivamente.

\begin{tabular}{|c|c|c|c|}
\hline 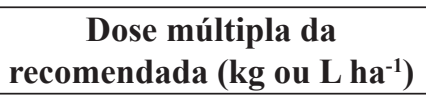 & Espécies & $\begin{array}{c}\text { Chlorimuron-ethyl+sulfometuron-methyl } \\
\text { Altura de plantas (cm) }\end{array}$ & Atrazine \\
\hline \multirow[t]{6}{*}{0} & Centeio & $8,2 \mathrm{c}^{1}$ & $8,9 \mathrm{bc}$ \\
\hline & Ervilhaca & $12,0 \mathrm{a}$ & $9,8 \mathrm{~b}$ \\
\hline & Nabo & $7,5 \mathrm{~cd}$ & $8,6 \mathrm{bc}$ \\
\hline & Soja-preta & $8,5 \mathrm{c}$ & $12,0 \mathrm{a}$ \\
\hline & Capim-colonião & $10,5 \mathrm{~b}$ & $9,2 \mathrm{~b}$ \\
\hline & Sem cobertura & $6,9 \mathrm{~d}$ & $6,9 \mathrm{c}$ \\
\hline \multirow[t]{6}{*}{$1 / 2$} & Centeio & $2,1 \mathrm{~b}$ & $10,9 \mathrm{a}$ \\
\hline & Ervilhaca & $1,5 \mathrm{~b}$ & $10,0 \mathrm{a}$ \\
\hline & Nabo & $1,5 \mathrm{~b}$ & $11,0 \mathrm{a}$ \\
\hline & Soja-preta & $2,2 \mathrm{~b}$ & $10,8 \mathrm{a}$ \\
\hline & Capim-colonião & $2,5 \mathrm{~b}$ & $9,9 \mathrm{a}$ \\
\hline & Sem cobertura & $5,5 \mathrm{a}$ & $9,1 \mathrm{a}$ \\
\hline \multirow[t]{6}{*}{1} & Centeio & $1,9 \mathrm{~b}$ & $8,3 \mathrm{~b}$ \\
\hline & Ervilhaca & $1,2 \mathrm{~b}$ & $12,4 \mathrm{a}$ \\
\hline & Nabo & $1,6 \mathrm{~b}$ & $12,0 \mathrm{a}$ \\
\hline & Soja-preta & $1,2 \mathrm{~b}$ & $11,0 \mathrm{a}$ \\
\hline & Capim-colonião & $1,4 \mathrm{~b}$ & $10,7 \mathrm{a}$ \\
\hline & Sem cobertura & $5,3 \mathrm{a}$ & $9,2 \mathrm{~b}$ \\
\hline \multirow[t]{6}{*}{2} & Centeio & $1,5 \mathrm{~b}$ & $9,2 \mathrm{bc}$ \\
\hline & Ervilhaca & $1,2 \mathrm{~b}$ & $10,4 \mathrm{ab}$ \\
\hline & Nabo & $1,1 \mathrm{~b}$ & $9,6 \mathrm{ab}$ \\
\hline & Soja-preta & $1,5 \mathrm{~b}$ & $11,7 \mathrm{a}$ \\
\hline & Capim-colonião & $0,9 \mathrm{~b}$ & $10,7 \mathrm{ab}$ \\
\hline & Sem cobertura & $4,2 \mathrm{a}$ & $7,2 \mathrm{c}$ \\
\hline \multirow{2}{*}{\multicolumn{2}{|c|}{$\begin{array}{l}\text { Média Geral } \\
\text { C.V. }(\%)\end{array}$}} & 3,85 & 9,93 \\
\hline & & 13,67 & 8,75 \\
\hline
\end{tabular}

${ }^{1}$ Médias seguidas de mesmas letras minúsculas na coluna, para cada dose dos herbicidas, não diferem entre si pelo teste de Tukey a $\mathrm{p}>0,05$. 
após cultivar as espécies de cobertura, pois, como pode ser visto na Tabela 6 , o solo que permaneceu sem cobertura demonstrou as menores alturas do pepino. A degradação de atrazine no solo é muito dependente de suas condições, segundo Krutz et al. (2009), a degradação pode ser de $50 \%$ em solos "adaptados" e reduzir para $20 \%$ em solos não "adaptados", após um período de 30 dias. O efeito da atrazine se potencializou pelo fato do tratamento sem cobertura não ter a capacidade de absorver e acumular o herbicida (Li et al., 2012).

Os tratamentos envolvidos na fitorremediação de solo provocaram um menor acúmulo de massa seca da parte aérea do pepino, ou seja, não ocorreu a descontaminação completa do solo que foi tratado com chlorimuron-ethyl + sulfometuron-methyl, principalmente com o incremento das doses (Figura 7A). Esses dados também corroboram

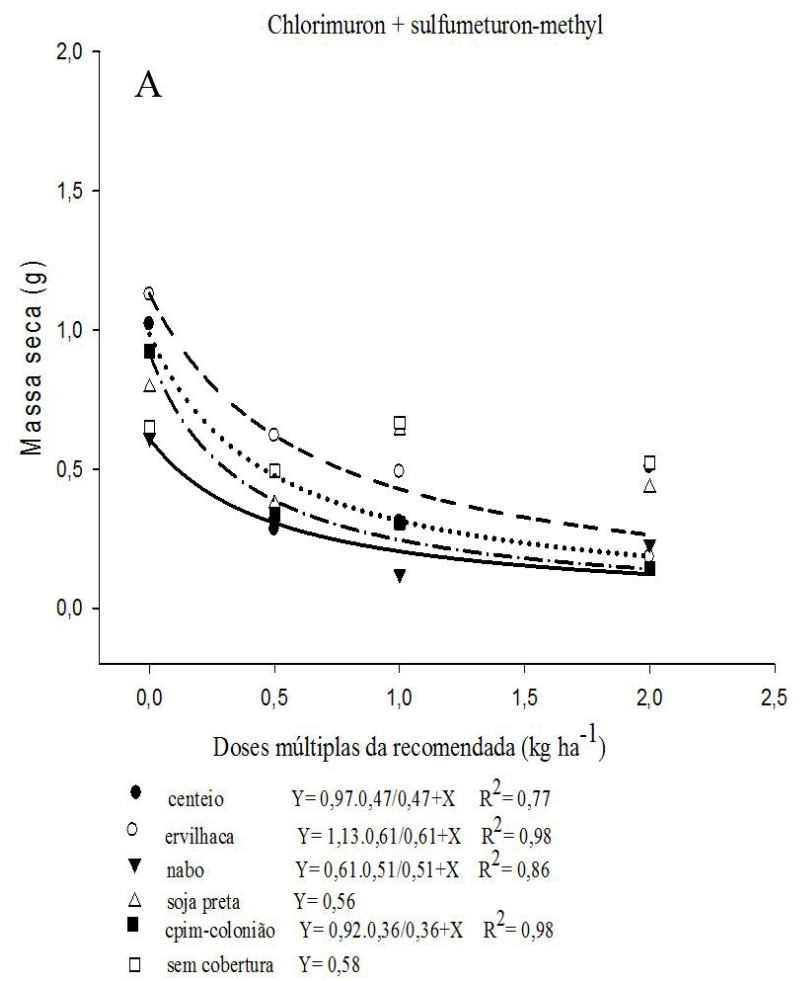

com os observados para a fitotoxicidade e altura de plantas de pepino, onde o herbicida chlorimuronethyl + sulfometuron-methyl apresentou efeito prejudicial mesmo após o cultivo de espécies com potencial fitorremediador. Ao se comparar as espécies entre si para cada dose de herbicida constatou-se que a ervilhaca e o solo sem cultivo (sem cobertura) apresentaram os maiores valores de massa seca do pepino ao se aplicar metade e uma vez a dose recomendada de chlorimuron-ethyl + sulfometuron-methyl (Tabela 7). A aplicação do dobro da dose recomendada de chlorimuron-ethyl + sulfometuron-methyl e o uso do centeio, da soja-preta e do tratamento sem cultivo ocasionaram os maiores acúmulos de massa seca do pepino.

Para o herbicida atrazine constatou-se que o cultivo do pepino, em sucessão a soja-preta, apresentou maior média de massa seca se comparado aos demais tratamentos (Figura 7 B). No entanto, o

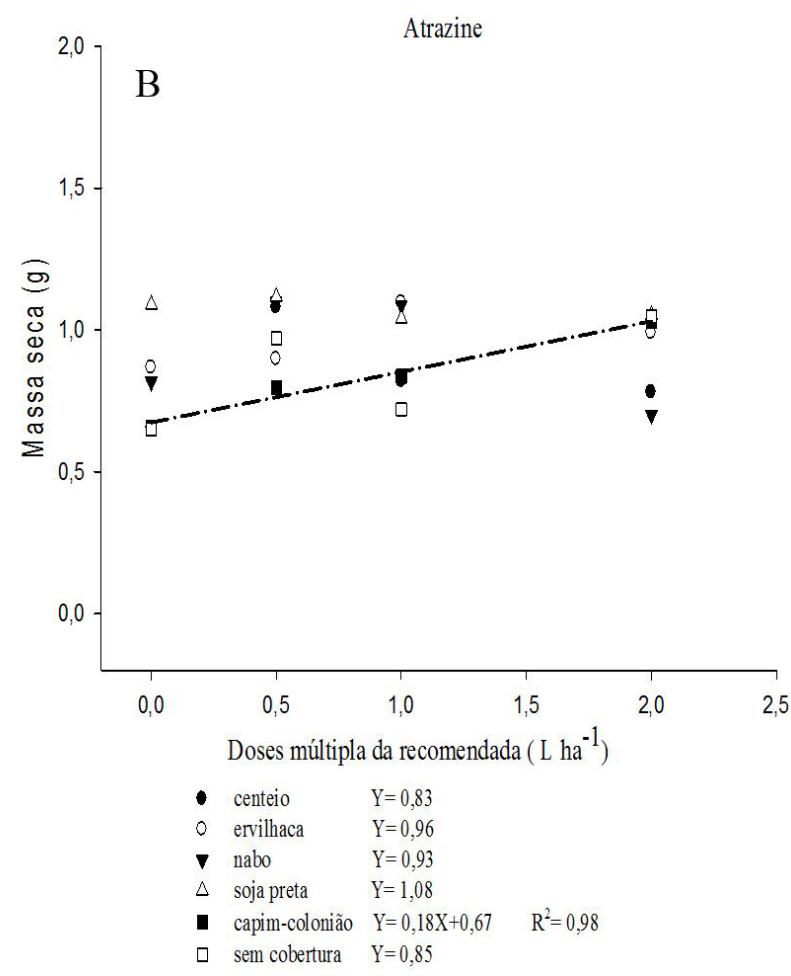

Figura 7. Massa seca da parte área das plantas de pepino em função da aplicação de doses múltiplas da recomendada do herbicida chlorimuron-ethyl + sulfometuron-methyl (A) e de atrazine (B) após a fitorremediação do solo com as coberturas; centeio $(\bullet)$, ervilhaca $(\circ)$, nabo $(\boldsymbol{\nabla})$, soja-preta $(\Delta)$, capim-colonião ( $\square$ ) e sem cobertura $(\square)$. 
único tratamento que apresentou ajuste dos dados ao modelo testado foi o uso de capim-colonião cultivado anteriormente ao pepino, e que mesmo ao se incrementar as doses de atrazine houve aumento linear no acúmulo de massa seca da cultura bioindicadora. Normalmente o aumento da dose de um herbicida ocasiona redução ou no mínimo mantêm-se o acúmulo de massa seca, os resultados, apesar de demonstrarem o contrário podem estar relacionados com um possível estímulo a recuperação das plantas. Pires et al. (2005), encontraram em seus resultados, redução da biomassa da soja cultivada após cultivos de adubos verdes, onde havia sido submetido aplicação de 1,0 $\mathrm{kg} \mathrm{ha}^{-1}$ de tebuthiuron, herbicida esse pertencente ao mesmo mecanismo de ação da atrazine.

Observou-se ao se comparar os cultivos com potencial fitorremediador entre si, que em todas as doses aplicadas de atrazine a ervilhaca demonstrou a maior produção de massa seca da parte aérea do pepino (Tabela 7). A ervilhaca, o nabo e a soja-preta ocasionaram os melhores resultados para o acumulo de massa seca do pepino ao se usar a meia e a dose recomendada de atrazine. O solo mantido sem cobertura ao se aplicar a dose recomendada de atrazine apresentou

Tabela 7. Massa seca (g) de plantas de pepino usado como espécie bioindicadora de solo fitorremediado por centeio, ervilhaca, nabo, soja-preta, capim-colonião e sem cobertura após a aplicação de doses de chlorimuron + sulfumeturon-methyl e atrazine, respectivamente.

\begin{tabular}{|c|c|c|c|}
\hline $\begin{array}{c}\text { Dose múltipla da } \\
\text { recomendada }\left(\mathrm{kg} \text { ou } \mathrm{L} \mathrm{ha}^{-1}\right)\end{array}$ & Espécies & $\begin{array}{c}\text { Chlorimuron+sulfumeturon-methyl } \\
\text { Massa seca (g) }\end{array}$ & Atrazine \\
\hline \multirow[t]{6}{*}{0} & Centeio & $1,0 \mathrm{a}^{1}$ & $0,7 \mathrm{~b}$ \\
\hline & Ervilhaca & $1,1 \mathrm{a}$ & $0,9 \mathrm{ab}$ \\
\hline & Nabo & $0,6 \mathrm{c}$ & $0,8 \mathrm{~b}$ \\
\hline & Soja-preta & $0,8 \mathrm{bc}$ & $1,1 \mathrm{a}$ \\
\hline & Capim-colonião & $0,9 \mathrm{~b}$ & $0,7 \mathrm{~b}$ \\
\hline & Sem cobertura & $0,7 \mathrm{c}$ & $0,7 \mathrm{~b}$ \\
\hline \multirow[t]{6}{*}{$1 / 2$} & Centeio & $0,3 \mathrm{~b}$ & $1,1 \mathrm{a}$ \\
\hline & Ervilhaca & $0,6 \mathrm{a}$ & $0,9 \mathrm{ab}$ \\
\hline & Nabo & $0,3 \mathrm{~b}$ & $1,1 \mathrm{a}$ \\
\hline & Soja-preta & $0,4 \mathrm{~b}$ & $1,1 \mathrm{a}$ \\
\hline & Capim-colonião & $0,4 \mathrm{~b}$ & $0,8 \mathrm{~b}$ \\
\hline & Sem cobertura & $0,5 \mathrm{ab}$ & $0,9 \mathrm{ab}$ \\
\hline \multirow[t]{6}{*}{1} & Centeio & $0,3 \mathrm{bc}$ & $0,8 \mathrm{bc}$ \\
\hline & Ervilhaca & $0,5 \mathrm{ab}$ & $1,1 \mathrm{a}$ \\
\hline & Nabo & $0,1 \mathrm{c}$ & $1,1 \mathrm{a}$ \\
\hline & Soja-preta & $0,6 \mathrm{a}$ & $1,0 \mathrm{ab}$ \\
\hline & Capim-colonião & $0,3 \mathrm{bc}$ & $0,8 \mathrm{bc}$ \\
\hline & Sem cobertura & $0,7 \mathrm{a}$ & $0,7 \mathrm{c}$ \\
\hline \multirow[t]{6}{*}{2} & Centeio & $0,5 \mathrm{a}$ & $0,8 \mathrm{bc}$ \\
\hline & Ervilhaca & $0,2 \mathrm{c}$ & $0,9 \mathrm{ab}$ \\
\hline & Nabo & $0,2 \mathrm{bc}$ & $0,7 \mathrm{c}$ \\
\hline & Soja-preta & $0,4 \mathrm{ab}$ & $1,1 \mathrm{a}$ \\
\hline & Capim-colonião & $0,1 \mathrm{c}$ & $1,0 \mathrm{a}$ \\
\hline & Sem cobertura & $0,5 \mathrm{a}$ & $1,0 \mathrm{a}$ \\
\hline Média Geral & & $\mathbf{0 , 5 0}$ & 0,91 \\
\hline C.V. $(\%)$ & & 17,94 & 10,18 \\
\hline
\end{tabular}

${ }^{1}$ Médias seguidas de mesmas letras minúsculas na coluna, para cada dose dos herbicidas, não diferem entre si pelo teste de Tukey a $\mathrm{p}>0,05$. 
o pior resultado para o acúmulo de massa seca do pepino cultivado em sucessão. Já no dobro da dose recomendada o nabo, seguido do centeio foram as coberturas de solo que demonstraram resultados inferiores para a massa seca do pepino ao se comparar com as demais espécies. Assis et al. (2010), verificaram que a espécie testada como fitorremediadora de solo Eleusine coracana (capim-pé-de-galinha-gigante) não foi eficiente em garantir pleno acúmulo de massa seca pelas plantas de soja, quando cultivadas em solo que recebeu duas doses do herbicida picloram (80 e $\left.160 \mathrm{~g} \mathrm{ha}^{-1}\right)$.

\section{Conclusões}

A soja-preta apresentou um maior potencial de fitorremediação de solo contaminado com chlorimuron-ethyl + sulfometuron-methyl.

Para o solo contaminado com atrazine, o capim-colonião foi a espécie que demonstrou potencial satisfatório como planta fitorremediadora.

O pepino demonstrou maior crescimento quando usou-se o capim-colonião como planta fitorremediadora de solo tratado com atrazine, principalmente nas maiores doses aplicadas.

Até a dose recomendada o centeio apresentou capacidade de despoluir o solo tratado com chlorimuron-ethyl + sulfometuron-methyl.

\section{Agradecimentos}

Ao CNPq, à FAPERGS e ao FINEP pelo auxílio financeiro à pesquisa e pelas concessões de bolsas.

\section{Referências}

Assis, R.L.; Procópio, S.O.; Carmo, M.L.; Pires, F.R.; Cargnelutti Filho, A.; Braz, G.B.P. Fitorremediação de solo contaminado com o herbicida picloram por plantas de capim pé de galinha gigante. Revista Brasileira de Engenharia Agrícola e Ambiental, v.14, n.11, p.1131-1135, 2010.

Correia, N.M.; Leite, G.J. Selectivity of the plant growth regulators trinexapac-ethyl and sulfometuron-methyl to cultivated species. Scientia Agrícola, v.69, n.3, p.194-200, 2012.

EMBRAPA - Empresa Brasileira de Pesquisa Agropecuária. Sistema brasileiro de classificação de solos. Brasília: Embrapa Solos, 2013. 353p.

FAOSTAT - Organização das Nações Unidas para Alimentação e Agricultura. Disponível em: $<$ http://www.fao.org/faostat/en/\#home >. Acesso em: 24 jun. 2017.

Galon, L.; Lima, A.M.; Guimarães, S.; Belarmino, J.G.; Burg, G.M.; Concenço, G.; et al. Potencial de espécies vegetais para fitorremediação de solos com herbicidas do grupo das imidazolinonas. Planta Daninha, v.32, n.4, p.719-726, 2014.

Hawton, D. The effectiveness of some herbicides for weed control in Panicum maximum and Brachiaria decumbens and some factors affecting the atrazine tolerance of these species. Tropical Grasslands, v.14, n.1, p.34-39, 1980.

Kraemer, F.; Marchesan, E.; Avila, L.A.; Machado, S.L.O; Grohs, M. Destino ambiental dos herbicidas do grupo das imidazolinonas. Planta Daninha, v.27, n.3, p.629-639, 2009.

Krutz, L.J.; Burke, I.C.; Reddy, K.N.; Zablotowicz, R.M.; Price, A. Enhanced atrazine degradation: evidence for reduced residual weed control and a method for identifying adapted soils and predicting herbicide persistence. Weed Science, v.57, n. 4, p.427-434, 2009.

Li, C.; Lv, T.; Liu, W.; Zang, H.; Cheng, Y.; Li, D. Efficient degradation of chlorimuronethyl by a bacterial consortium and shifts in the aboriginal microorganism community during the bioremediation of contaminated-soil. Ecotoxicology and Environmental Safety, v.139, p.423-430, 2017.

Li, X.; Wu, T.; Huang, H.; Zhang, S. Atrazine accumulation and toxic responses in maize Zea mays. Journal of Environmental Sciences (China), v.24, n.2, p.203-208, 2012. 
Mancuso, M.A.C.; Negrisoli, E.; Perim, L. Efeito residual de herbicidas no solo ("carryover"). Revista Brasileira de Herbicidas, v.10, n.2, p.151-164, 2011.

Merini, L.J.; Bobillo, C.; Cuadrado, V.; Corach, D.; Giulietti, A.M. Phytoremediation potential of the novel atrazine tolerant Lolium multiflorum and studies on the mechanisms involved. Environmental Pollution, v.157, n.1, p.3059-3063, 2009.

Osiecka, A.; Minogue, P. Selective herbicides for bald cypress restoration cultivation. Weed Technology, v.26, n.3, p.460-468, 2012.

Pires, F.R.; Souza, C.M.; Silva, A.A.; Procópio, S.O.; Ferreira, L.R. Fitorremediação de solos contaminados com herbicidas. Planta Daninha, v.21, n.2, p.335-341, 2003.

Pires, F.R.; Souza, M.; Cecon, P.R.; Santos, J.B.; Tótola, M.R.; Procópio, S.O. et al. Inferências sobre atividade rizosférica de espécies com potencial para fitorremediação do herbicida tebuthiuron. Revista Brasileira de Ciência do Solo, v.29, n.4, p.627-634, 2005.

Procópio, S.O.; Santos, J.B.; Pires, F.R.; Silva, A.A.; Santos, E.A.; Ferreira, L.R. Phytoremediation of soil contaminated with trifloxysulfuron-sodium by Stizolobium aterrimum. Planta Daninha, v.23, n.4, p.9-16, 2005.

Reis, R.M.; Souza, M.F.; Queiroz, G.P.; Siebert, I.G.; Silva, D.V.; Fereira, E.A.; Silva, A.A. Tolerância do girassol a herbicidas aplicados em pós-emergência. Revista Brasileira de Herbicidas, v.13, n.1, p.15-22, 2014.

Santos, D.P.; Braga, R.R.; Guimarães, F.A.R.; Passos, A.B.T.J.; Silva, D.V.; Santos, J.B.; et al. Determination of bioindicators of auxinic herbicides residues. Revista Ceres, v.60, n.3, p.354-362, 2013.

Santos, G.; Francischini, A.C.; Constantin, J.; Oliveira Junior, R.S. Carry-over effect of S-metolachlor and trifluralin on bean, corn and soybean crops. Planta Daninha, v.30, n.4, p.827-834, 2012.

SBCPD - Sociedade Brasileira da Ciência das Plantas Daninhas. Procedimentos para instalação, avaliação e análise de experimentos com herbicidas. Londrina: SBCPD, 1995. 42p.

Silva, A.A.; Ferreira, F.A.; Ferreira, L.R. Herbicidas: classificação e mecanismos de ação. In: Silva, A.A.; Silva, J.F. (Ed.). Tópicos em manejo de plantas daninhas. Viçosa: UFV, Cap.3, p.83$148,2007 \mathrm{a}$

Silva, A.A.; Vivian, R.; Oliveira Junior, R.S. Herbicidas: comportamento no solo. In: Silva, A.A.; Silva, J.F. Tópicos em manejo de plantas daninhas. Viçosa: UFV, Cap.5, p.189-248, 2007 b.

Vasconcellos, M.C.; Pagliuso, D.; Sotomaior, V.S. Phytoremediation: A proposal of soil decontamination.

Estudos de Biologia: Ambiente e Diversidade, v.34, n.83, p.261-267, 2012. 